\title{
A Study on Teachers' Roles in English Autonomous Learning
}

\author{
Haizhen Zhao a , Qiuping Huang ${ }^{b}$ \\ College of Foreign Studies, Guilin University of Electronic Technology, Guilin, Guangxi, China \\ a7629332@qq.com, b122407609@qq.com
}

Keywords: autonomous learning; mediation theory; roles

\begin{abstract}
Effective autonomous learning is a process in which learners, teachers and environment interact with each other. In this process teachers play a significant role. The paper explores the proper roles that teachers are expected to play in English autonomous learning. Firstly, the paper introduces the theoretical basis for teachers' mediation in English autonomous learning. Secondly, the paper states the shift of teachers' roles in autonomous learning. Thirdly, the paper suggests some specific roles for teachers in English autonomous learning.
\end{abstract}

\section{Introduction}

The term "autonomy" was first coined by Holec ${ }^{[1]}$ to refer to "the ability to take charge of one's own learning”. Different scholars have defined the term in different ways. These concepts have developed independently in different geographical areas and therefore they have been defined using different terms like autonomous learning, self-access learning, self-directed learning, etc. Whatever the name they all emphasize the responsibility of learners for their own learning. In this paper, the author uses "autonomous learning" to refer to the learning process in which a learner take responsibility of his own learning.

Since the introduction of this concept it has attracted considerable attentions in the field of language teaching and a systematic research was made in terms of theory as well as practice. Despite the rich harvest the research is far from perfection. For instance, some researches highlight a learner's ability of independent learning while not enough emphasis was paid on teachers' roles in autonomous learning. In practice, learning environment is greatly improved with multi-media classrooms and self-access learning centers widely established in schools at various levels. Unfortunately monitoring and managing of learning process was not made, thus affecting the efficiency of autonomous learning. Among the problems mentioned above much was attributed to people's attitude towards teachers' roles in autonomous. Some tend to think that autonomous learners should learn individually and independently of their teachers and instructors. There are still others who exaggerated the function of learner-supporting facilities but undermined the roles of teachers or instructors. Therefore it is imperative to study the proper roles of teachers in autonomous learning process. Only in this way can we get a thorough understanding and build an appropriate relationship between learners and teachers in the learning process. So this paper aims to explore the involvement of teachers in autonomous learning. Besides some suggestions will be given on what roles teachers should play in students' process of autonomous learning.

\section{The theoretic basis for teachers' roles in autonomous learning}

The theoretical basis for teachers' roles in autonomous learning can be traced back to mediation theory. According to William \& Burden ${ }^{[2]}$ "Mediation, a term used by psychologists of the social interactionist school, refers to the role played by other significant people in learners' lives, who enhance their learning by selecting and shaping the learning experiences presented to them. That important person in the learning process is called a mediator. Basically the secret of effective learning rests with the nature of social interaction between two or more people with different cognitive levels. The role of the mediator such as a parent, teacher or a peer is to find ways of helping others to learn.” In this paper the term "involvement” refers to the proper roles that teachers 
play in English learners' autonomous learning in order to promote their learning.

The theory of mediation was developed by Feuerstein, an Israel psychologist and educator. Concerning learning and development of children Feuerstein believes that right from birth a child's learning is shaped by intervention of significant adults. He states that a child's learning, right from his birth, is shaped by the intervention of significant adults around him. Feuerstein refers to these important figures in the child's learning as mediators or mediating adults, and the experiences that they provide as mediated learning experiences.

Compared with the role of traditional teachers as disseminator of information, the role of a mediator is strikingly different. Williams \& Burden explained the differences as follows:

First, mediation must involve empowering. That means it helps learners to acquire knowledge skills and strategies needed to make progress, deal with problem, function effectively in a certain culture and a changing society, and to meet fresh and unpredictable challenges. It also involves helping learners to become autonomous with the fundamental aim of cultivating independent thinkers and problem--solvers.

Secondly, mediation concerns interaction between mediators and learners, and learners are active participants in the learning process.

Thirdly, in the process of mediation reciprocation is highlighted. That means it is important for learners to understand and accept the intentions of the mediator (sometimes the teacher). The learner is expected to be ready and willingly to carry out tasks presented and be informed of what should be done and why.

Fourthly, it is worth noting that learner autonomy involves more than providing suitable self-accessed learning materials. A mediator also needs to help learners to interact with those materials in various manners until they become really self-directed learners.

In order to provide learners with learning experiences that are truly educational, a teacher or other adult can "mediate" in a variety of ways. Feuerstein identifies and elaborates twelve features of mediation ${ }^{[3]}$.

Significance: Significance emphasizes that any learning task must have value or personal meaning to the learners. It means that a teacher need to make learners realize the significance of a learning task so that they can see the personal value of it, and in a broader culture context.

Purpose beyond here and now: Purpose beyond here and now, also called "transcendence" by Feuerstein, focuses on the reason of learning. Williams \& Burden points out that the learners need to understand the transcendence of the learning experience, identifying rules and recurring themes, leading to learning beyond the immediate time and place.

Shard intention: When presenting tasks and giving directions teachers should convey to the students the purpose of each learning task and explain exactly what they are expected to do.

A sense of competence: People who feel competent may perform better than those who do not, irrespective of their real level of knowledge.

Control of own behaviors: This means learners, in their learning process, are aware of monitoring and adjusting their behaviors with the help of self-discipline and certain skills.

Goal-setting: Every single person has the necessity to set his goals and to plan ways to achieve them in life, and of course in learning. Setting goals makes a person's learning directed and effective because goal-setting helps motivate him to achieve more than those without any goals or directions.

Challenge: According to Feuerstein the mediation of challenge in learning and in life in general is considered to prepare an individual for adjusting to the complexity and the novelty of the world.

Awareness of change: Feuerstein views human beings as a modifiable entity and he supports an active approach to changes, seeing humans accessible to physical, emotional, cognitive and social changes in all possible contexts and directions.

A belief in positive outcomes: When a person faces a challenging situation. Knowing that something is possible makes the involved individual become committed to the search for ways to turn the possible into a materialized experience.

Sharing: Though competition is a motivating factor in making progress and thus is encouraged 
among learners. The role of sharing and cooperation cannot be denied since they help form social networks and promote exchanges of skills, knowledge and attitudes.

Individuality: Unlike sharing mentioned previously, individuality refers to the need of an individual to keep his uniqueness--feeling and thinking differently from others, and to meet his need for the development of his personality.

A sense of belonging: Each individual needs to develop a social and emotional connection with the world in which he lives in.

The twelve features of mediation provides ways that instructors or teachers can take to promote learning. They cover factors that a learner of any type may encounter like cognitive needs and emotional needs. So they are meaningful and applicable for learning in a general sense including English autonomous learning.

\section{The shift of teachers' roles in autonomous learning}

\begin{tabular}{|l|l|}
\hline Student & Teacher \\
\hline Planner (of own learning ) & Counsellor \\
\hline Assessor (self and others) & Assessor \\
\hline Evaluator & Evaluator \\
\hline Motivator (of self) & Materials developer \\
\hline Administrator (of own learning) & Manager \\
\hline Organizer ( of own learning) & Administrator \\
\hline Advisor (to other learners) & Organizer \\
\hline
\end{tabular}

Implementation of autonomous learning requires changes in roles of learners, teachers and institutions. Learners need to become more aware of their central role in the process of learning. They will make more responsibilities for their learning. At the same time, the roles of teachers will also change dramatically as their students engage in autonomous learning. Teachers need to learn new skills to take on their new roles. Some of the "new" roles for teachers may seem familiar. However, these roles have to be redefined when the new roles of learners are also taken into account. The following figure shows shifting roles of students as well as teachers consequently.

Compared with traditional teaching the shifting of teachers' roles in autonomous learning can be found in the following three aspects. Firstly, teachers promote learning in an indirectly way rather than a direct one. In the traditional educational setting teachers instruct learners mainly through transmitting knowledge. In this process teachers play a leading role, who decide the content, time and pace of learning. Learners, on the other hand, follow their teachers' instructions. In autonomous learning, teachers facilitate learning by helping learners in various ways like goal setting, needs analysis, self-control, etc. That is to say teachers promote learning by helping students become more conscious and independent learners. In the process learners play a dominant part. They have to make decisions by themselves and get help from their teachers when needed. Secondly, teachers take on diverse roles rather than simple roles. In autonomous learning teachers take on more "new" roles like manager, counsellor, administrator, evaluator, etc. For example, they manage the whole learning process, evaluate the effectiveness of learning, promote learning awareness and help solve problems of learning. Thirdly, teachers' pay more attention to learners' individual needs. In autonomous learning, learners' personal needs are highly valued and satisfied. In order to promote autonomous learning, learners' needs, learning styles, interests are taken into consideration.

In summary, teachers need to realize the shift of their roles in autonomous learning and learn and adapt to them in order to promote autonomous learning among their students.

\section{Teachers' roles in autonomous learning}

In this part some specific ways are suggested to promote autonomous learning through teachers' involvement. 


\subsection{Play the role of a motivator by raising students' awareness of autonomous learning}

The awareness of autonomy is a preliminary stage in learner autonomy. In this stage it is essential for teachers to help students realize they should take responsibility for their own learning. In terms of English courses, teachers need to inform students of the overall requirements, learning goals and arrangement of college English at the very beginning of their college learning in order to make them ready psychologically. Besides, making students understand the meaning of autonomous learning is an important task for teachers. Because it will have a great effect on their way to be autonomous learners. In order to build up their self-confidence teachers can remind learners that autonomy doesn't equal to mere freedom, instead they can get teachers' help and guidance when needed. This will reduce learners' pressure and fear of the new learning approach.

\subsection{Play the role of a counsellor by facilitating autonomous learning}

In the traditional English teaching context, teaches act mores as transmitters of knowledge and learners as receivers. This turns out to impose a negative effect on English teaching, in which learners' creativity and personal needs are ignored due to teachers' failure to realize that learners are active participants in the English language learning. Therefore teachers should find some ways in facilitating learners become independent and autonomous learners. Teachers also need to make students realize that in the autonomous learning context teachers are not mere knowledge transmitter but play the role as facilitator, guide, assessor, psychological coordinator, source of information, etc.

\subsection{Play the role of a mediator by creating an autonomy-supportive learning environment}

Learning environment has a crucial effect on language learning and will influence learners' motivation in a positive or negative way. Self-determination theory (SDT), one of the motivation theories, divides learning contexts into two groups as autonomy-supportive and controlled climates according to teachers' behaviors. Autonomy-supportive climates are associated with teachers' behaviors which facilitate students' learning, and mostly related to intrinsic motivation, higher perceived competence, higher academic achievement and classroom engagement. These climates have many positive influences on students' competence, autonomous motivation, classroom participation, conceptual understanding, creativity, achievement, etc ${ }^{[4]}$. Some of the characteristics of the teachers in those contexts are as follows: listening to students carefully, creating opportunities for students to choose, nurturing inner motivational resources, using informational language and so forth.

Based on Feuerstein's mediation theory there are several ways teachers can mediate in order to create an autonomy-supportive environment. Firstly, teachers can encourage a sense of belong among their students. Peer learning and group work are effective ways to stimulate sense of belonging. In other words, teachers should encourage students to work in pairs or groups and make their own contributions. Secondly, teachers ought to cultivate a belief in positive outcomes. Students will undoubtedly face many challenges in their learning process. Only when they believe that they can work out a solution can they make efforts to solve those challenges and difficulties. Therefore, teachers have the duty to make their students believe that they can always find a solution to even intractable problems as long as they keep trying and stay committed to them. Thirdly, teachers need to respect students' individuality. According to Feuerstein, individuality refers to the need of an individual to keep his uniqueness--feeling and thinking differently from others, and to meet his need for the development of his personality. Therefore when promoting autonomy, students' individuality should be valued and respected.

In summary, the learning atmosphere in autonomous learning should be harmonious and encouraging. In such an environment students' interests and personalities are respected and cultivated. They have a sense of belonging in their learning environment in which a favorable learning atmosphere will be created and students will be stimulated in autonomous learning. 


\subsection{Play the role of a materials provider by facilitating students in extra-curricular learning}

In addition to classroom learning, students also need to get involved in English learning out of class for higher English competence. Because in extracurricular learning learners have more freedom and control over their learning activities, which is one of the main characteristics of autonomous learning. If well planned and organized, learners' autonomy is sure to be cultivated and developed through extracurricular activities. In this process teachers can involve students learning and promote their autonomy in the following aspects. On one hand, provide students with abundant and appropriate learning materials and resources in order to meet their needs for autonomous learning. Concerning the choice of learning materials and resources there are some aspects that teachers need to take into consideration. Students' learning capacity needs to be considered. It can't be too difficult to get beyond students' current language capacity or too easy to make students lose interests. It should be a little higher above students' current level so that they can handle it with their prior knowledge, interests and curiosity. The degree of authenticity is another factor to be considered. They can be newspapers, magazines, TV, radio, online resources and so on. McGarry agrees that authentic materials play a significant role in promoting learner autonomy through contribution in the two areas: (a) the matching of language learning opportunities to the needs and interests of individual students and (b) the creation of conditions under which students can most successfully exploit those opportunities ${ }^{[5]}$.

\subsection{Play the role of a strategy supporter by providing students with proper learning strategies}

To become an autonomous learner students must learn how to monitor and evaluate their own English learning, which is an indispensable part of learner autonomy. Copple \& Bredekamp states the purposes and significance of self-assessment in the following ways: it helps learners diagnose their own strong and weak areas; it makes them compare their present level with that they wish to achieve; it helps them to be more motivated; And it lets them develop their own criteria for monitoring the progress they made ${ }^{[6]}$. To achieve self-assessment students need proper strategies. Teachers are obliged to equip students with meta-cognitive strategies. That is to say the strategies to make plans for learning, thinking about learning process, monitoring of comprehension and evaluating of learning after an learning task or activity is completed. With learning strategies students will achieve self-management of their learning and self-evaluation of their learning, which can promote the efficiency of autonomous learning.

\section{Conclusions}

English autonomous learning is a challenge for both students and teachers. In this process teachers should realize the shift of their roles and equip them with the new roles. Only in this way can they facilitate learning effectively and help their students become effective and successful autonomous learners in their process of English learning.

\section{Acknowledgements}

This work is supported by Research on the Construction of an Effective Multi-modal English Oral Output Teaching Mode in the Cloud Environment (Grant No. 2016JGB223), Guangxi Higher Education Undergraduate Teaching Reform Project.

\section{References}

[1] Holec, H: Autonomy and Foreign Language Learning (Pergamon Press, Oxford 1981).

[2] William, M. and Burden, R. L: Psychology for Language Teachers (Press of the University of Cambridge, Cambridge 2000).

[3] Feuerstein, R, Klein, P. S and Jannenbaum, A. J: Mediated Learning Experience: Theoretical, Psychological, and Learning Implications (Freund, London 1991). 
[4] Ames, C. and Arthur, J: Achievement Goals in the Classroom: Students' Learning Strategies and Motivation Processes. Journal of Educational Psychology.Vol. 80 (1998), p. 260-267.

[5] McGarry, D: Learner Autonomy 4: The role of Authentic Texts (Authentik, Dublin 1995).

[6] Copple, C. and Bredekamp, S: Developmentally appropriate practice in early childhood programs (National Association for the Education of Young Children, Washington, D.C 2009 ). 